\title{
Discrimination of the number three by a raccoon (Procyon lotor)
}

\author{
HANK DAVIS \\ University of Guelph, Guelph, Ontario, Canada
}

\begin{abstract}
This paper reports the establishment of a discrimination based upon the number three in a male raccoon. Following a 6-month training period, the subject was able to select a clear Plexiglas cube containing 3 objects (grapes or small metal bells) from an array of cubes containing $1,2,3,4$, and 5 items. The results confirm previous reports of "intelligence" in the raccoon, and extend the number of species in which sensitivity to number has been demonstrated (see review by Davis \& Memmott, 1982).
\end{abstract}

There is a large and rather colorful history of attempts to use number-related stimuli to control the behavior of animals. In addition to work with legendary "clever" horses like Hans (Watson, 1914), there has also been rigorous and empirically supported evidence of animal behavior brought under the control of number. We have recently surveyed this literature and summarized successful reports in species as diverse as rats, ravens, seals, chimpanzees, crows, mice, monkeys, and magpies (Davis \& Memmott, 1982).

In addition to an abundance of anecdotal reports, the evidence for animal sensitivity to number stems from the use of a variety of techniques - from conventional laboratory methodology to more exotic seminatural conditions. In some cases, the evidence focuses upon the animal's ability to "count," that is, to enumerate objects by applying a series of cardinal labels. In most cases, however, it has been virtually impossible to identify a behavioral analogue of such a cardinal chain. Nevertheless, the term "counting" has been applied to cases of behavioral control when all nonnumerical properties of the stimulus environment (e.g., visual, auditory, or temporal) have been controlled.

For example, Hicks (1956) worked with rhesus monkeys and required his subjects to select the correct stimulus card from two or three alternatives. Each of the cards depicted arrays of between one and five geometric shapes. The correct response was determined solely on the basis of the number three; the subject had to disregard the color, size, spatial arrangement, and geometric form of the objects. Like many investigators in the field, Hicks reported that discriminative control by the "concept of threeness" could be established, but only after extensive training.

\footnotetext{
This research was supported in part by Grant A06973 from the Natural Science and Engineering Research Council of Canada. The author is indebted to Lisa Nadeau for her skillful and sensitive help throughout. Thanks are extended to Harry Hurwitz, Sheree Bradford, Melody Albert, and Susan Simmons for their comments on this manuscript. Reprints may be obtained from the author, c/o Department of Psychology, University of Guelph, Guelph, Ontario, Canada N1G 2 W1.
}

In the present experiment, we examined the possibility of establishing discriminative control by the number three in a raccoon, a subject that has not yet appeared in the counting literature. In fact, despite research on its physiology and ecology (e.g., Barash, 1974; Munger \& Pubols, 1972; Murphy \& O'Leary, 1973; Pubols \& Leroy, 1977; Rabinowitz, 1981), the raccoon has not been a popular subject for conditioning research. This point was underscored by Breland and Breland (1961), who detailed their problems in training raccoons, and described this subject, along with cockatoos and reindeer, as being among the more "unlikely" with which they had worked.

The reluctance to use raccoons in behavioral research probably has more to do with their lack of manageability than with their lack of intelligence. Certainly, in anecdotal terms, the raccoon is known, perhaps to a fault, for its skill as a "problem solver." Moreover, the early literature is replete with reports of raccoon "intelligence" (e.g., Cole, 1907; Davis, 1907).

More recent studies of the raccoon's discriminative abilities have found it to be an adequate, but not outstanding, performer. Most of these studies have focused upon visual discrimination (e.g., Johnson \& Michels, 1958; Munn, 1930; Warren \& Warren, 1962). In a typical experiment, Shell and Riopelle (1957) examined the raccoon's ability to form "learning sets," that is, to show interproblem improvement across a series of visual discrimination tasks. They concluded that the raccoon's performance never attained the proficiency of primates, but was comparable to that of cats.

In the following experiment, we attempted to teach our raccoon using a procedure similar to that of Hicks (1956); viz, the correct response was determined solely on the basis of the number three. However, unlike Hicks, we presented our subject with arrays of five items from which to choose. Moreover, because some controversy exists regarding the raccoon's visual acuity (cf. Bierens de Haan, 1932; Cole, 1907; Fields, 1936), our stimuli were presented in a manner that allowed the subject to regulate the distance between himself and the stimulus array. 


\section{METHOD}

\section{Subject}

The subject was a male raccoon ("Rocky"). He was orphaned at approximately 1 month when his mother was killed by an automobile. Rocky was adopted as a pet and bottle-fed. After 3 months, he became too rambunctuous for family life and was taken to a supervised conservation area, where he lived in a seminatural state (i.e., allowed to range widely with food and water available). When the subject was approximately 8 months old, he was transferred to the University of Guelph Animal Housing facility. Following a series of immunizations and a full veterinary examination, he began service as an experimental subject.

Throughout the 6-month course of the experiment, Rocky lived in an individual cage approximately $4 \times 3 \times 3 \mathrm{ft}$ (length $\times$ width $\times$ height). The cage was located in a $10 \times 12 \mathrm{ft}$ private room. All experimental sessions were conducted in this room, which contained a second (unoccupied) cage and a wooden table. A 12-h light/dark cycle was in effect throughout the experiment. The subject was free to explore the room during each of two daily experimental sessions, as well as during the time his cage was cleaned every day. Free food and water were available throughout his confinement.

\section{Apparatus}

The test apparatus, illustrated in Figure 1, consisted of five clear Plexiglas cubes with $10-\mathrm{cm}$ surfaces. Four of the five cubes could be sealed by inserting a $1.0-\mathrm{cm}$ setscrew into the lid. The fifth cube was visually identical to the others, but the setscrew, which was permanently inserted into the lid, had been severed midway to allow the lid to open. The front lip of each cube top overlapped the cube by approximately $0.5 \mathrm{~cm}$ to facilitate opening the cube, that is, by flipping back the top.

\section{Procedure}

The basic procedure consisted of "baiting" each cube with a different number of objects, ranging from one to five, and requiring the subject to select the cube that held three. Only the cube holding three objects could be opened. If the subject attempted to open one of the "incorrect" cubes, using either his paw or his muzzle, an error was recorded for that trial.

The subject was initially exposed to only the target 3-cube. For a 4-day adaptation period, he was taken from his cage twice daily and allowed to play with the cube. He rapidly learned to open the cube and eat the contents. The cube was always baited with three grapes during this period. Discrimination training began with the introduction of a second cube, which contained one grape. Once successful performance stabilized under these conditions, a third



Figure 1. Raccoon exploring Plexiglas cubes prior to formal training. Cube on left contains three grapes.
Table 1

Summary of Procedural Changes

\begin{tabular}{|c|c|}
\hline Sessions & Procedure \\
\hline $1-4$ & Habituation to target cube containing three grapes. \\
\hline $5-48$ & Introduction to second cube: 1 vs. 3 . \\
\hline $49-66$ & $\begin{array}{l}1 \text { vs. } 3 \text { continued: Subject no longer reliably eats grapes on } \\
\text { successful trials; raisins introduced as reinforcer. }\end{array}$ \\
\hline $67-82$ & $\begin{array}{l}1 \text { vs. } 3 \text { continued: Positive social reinforcement (opportunity } \\
\text { for play with trainer) introduced. }\end{array}$ \\
\hline $83-162$ & $\begin{array}{l}\text { Third cube introduced: } 1 \text { vs. } 3 \text { vs. } 5 \text {. Three grapes available } \\
\text { as reinforcement but rarely eaten. Use of raisins and/or } \\
\text { chocolate-covered raisins maintained. Social reinforcemen } \\
\text { maintained. Error contingency (time-outs) introduced. }\end{array}$ \\
\hline $163-229$ & Fourth cube introduced: 1 vs. 3 vs. 5 vs. 6 . \\
\hline $230-257$ & Four cubes continued. Toy bell introduced as reinforcer. \\
\hline $258-290$ & $\begin{array}{l}\text { Four cubes continued. Grapes replaced by toy bells. Successfu } \\
\text { trial followed by } 5 \text {-min opportunity to play with three toy bells } \\
\text { Social reinforcement maintained. }\end{array}$ \\
\hline $291-304$ & Fifth cube introduced: 1 vs. 3 vs. 4 vs. 5 vs. 6. \\
\hline $305-326$ & $\begin{array}{l}\text { Five cubes continued. Choices changed to } 1 \text { vs. } 2 \text { vs. } 3 \text { vs } \\
4 \text { vs. } 5 \text {. }\end{array}$ \\
\hline
\end{tabular}

cube and ultimately a fourth and fifth were added to the array from which the subject had to choose. The gradual increase to five cubes is summarized in Table 1.

Grapes of different sizes (ranging from 10 to $25 \mathrm{~mm}$ in length) were used throughout the experiment in order to assure that size or weight did not become reliable cues for solution of the problem. Thus, for example, there were sessions in which the three-grape array was larger and heavier than four- and five-grape arrays. Although fresh grapes were initially used as bait, the subject's gradual disinterest in this food caused us to rely first on external reinforcers for each trial (i.e., the delivery of another reward following the selection of the target cube), and ultimately to change the contents of the cubes altogether in order to maintain the subject's interest. This series of procedural changes is described in Table 1.

Throughout the experiment, the subject was run twice daily for 7 days a week. Each session consisted of three trials, during which the baited cubes were placed before the subject on the floor. On each trial, the cubes were shuffled and arranged in a row according to a sequence determined by a random-number table. The Plexiglas cubes were cleaned with soap and water following each session to minimize olfactory cues.

The subject did not always "cooperate" by examining the cubes that were placed before him at the start of a trial. On many occasions, he continued to play or explore the room despite the appearance of the cubes. Neither calling him nor the systematic use of a signal (whistle) at the start of each trial facilitated matters on such occasions. Thus, both intertrial periods and session lengths remained variable, depending upon the activity level and attention span of the subject.

As indicated in Table 1, several procedural modifications were made when the subject no longer reliably ate the grapes following a successful trial. Ultimately, stable performance was achieved by baiting the cubes with toys (small metal bells) rather than food. Reinforcement consisted of the opportunity to play with the three bells. A 5-min period was provided for this activity, which typically consisted of the subject's "batting" them along the floor in catlike fashion and/or washing them in a pail of water (see Figure 2). Perhaps the most consistent reinforcer, however, was social: the opportunity to play with and receive praise from the handler (see Figure 3).

Only one trainer was used throughout the experiment-a 25-yearold female (L.N.). During each session, she recorded the subject's choices on each trial and noted behavioral patterns that often led 


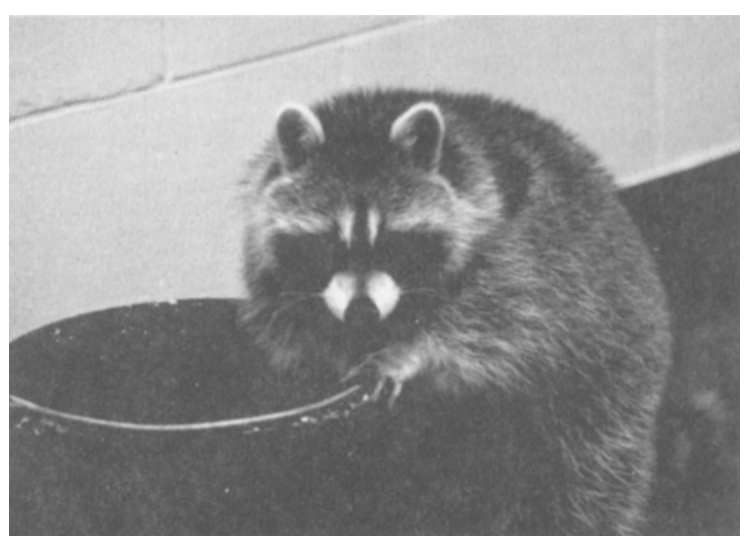

Figure 2. After he has successfully removed three metal bells from Plexiglas cube, raccoon washes them in pail of water.



Figure 3. The opportunity to socialize with the handler remained an important source of reinforcement throughout the experiment.

to procedural modifications. A portion of the trials were videotaped and scored by independent observers. Interobserver reliability in these cases exceeded $95 \%$.

Midway in the course of training, following the introduction of the third cube, it became necessary to introduce an error contingency. Because of the powerful nature of social reinforcement, it was decided to implement a 60-sec time-out (TO) period immediately following the selection of an incorrect cube. During this period, the trainer immediately scolded the subject, removed the 3-cube, and left the room. The potency of this procedure was confirmed not only by the data, but also by the raccoon's emotionally distressed vocalizations.

\section{RESULTS}

Rocky's performance during each phase of the experiment was measured in terms of the number of trials on which he opened the cube holding three objects. If he first attempted to open any of the alternate cubes, the trial was recorded as an error. The data were evaluated in blocks of 25 trials, and their significance level was determined using a binomial expansion based upon the number of alternatives in the array.

Table 2 indicates that performance improved under each successive condition and reached a highly significant level in the final test situation. The subject reliably selected and opened the cube containing three items from an array of cubes representing the numbers $1,2,3,4$, and 5 .

Although session length and intertrial periods tended to be quite variable, the duration of the trials themselves were relatively brief. Once a trial had begun, the subject rarely spent much time selecting a cube. In the majority of cases, he approached the array from either the right or left. When the target cube was identified, there was typically no further searching on that trial, regardless of the number of cubes remaining. Although most trials involved visual search at fairly close distance $(10-20 \mathrm{~cm})$, there were occasions on which Rocky appeared to scan the contents of the cubes during his approach to the array. On these occasions, he often approached the target cube directly and opened it without examining the remaining choices.

During trials involving four cubes (1-3-5-6), virtually all errors involved the selection of cubes that held numbers larger than three, that is, five or six items. This pattern was maintained following the increase to five cubes. Of 19 errors made during the final 75 trials, only 4 involved numbers smaller than the target three (three incorrect selections of the number two, and one of the number one).

\section{DISCUSSION}

We believe we have demonstrated discrimination of the number three in a raccoon subject. In reaching this conclusion, we have considered not only the extremely high probability levels associated with his performance, but also the number of alternative stimulus dimensions for which we have controlled. These include olfactory cues, spatial cues (location of the target cube in the array), and size or density of the stimulus (grapes of different sizes were used to avoid solution on the basis of size of the configuration). Moreover, we have transferred the discrimination, without noticeable disruption, from green grapes to small metal bells.

We have not identified the mechanism by which the raccoon correctly selected the number three. Unlike our previous experiments with rats (e.g., Davis \& Memmott, 1983), in which the to-be-counted events were presented

Table 2

Performance Data and Significance Levels Based Upon Binomial Expansion

\begin{tabular}{lcl}
\hline \multicolumn{1}{c}{ Condition/Session Block } & $\begin{array}{c}\text { Number } \\
\text { Correct }\end{array}$ & \multicolumn{1}{c}{ Probability } \\
\hline 3 Cubes/Final & $19 / 25$ & $<.00001$ \\
4 Cubes/Final-3 & $12 / 25$ & $<.01$ \\
4 Cubes/Final-2 & $15 / 25$ & $<.002$ \\
4 Cubes/Final-1 & $18 / 25$ & $<.000001$ \\
4 Cubes/Final & $21 / 25$ & $<.000000001$ \\
5 Cubes $(1-3-4-5-6) / F i n a l-1$ & $20 / 25$ & $<.000000001$ \\
5 Cubes $(1-3-4-5-6) /$ Final & $22 / 25$ & $<.00000000001$ \\
5 Cubes $(1-2-3-4-5) /$ Final-2 & $17 / 25$ & $<.000001$ \\
5 Cubes $(1-2-3-4-5) / F i n a l-1$ & $19 / 25$ & $<.00000001$ \\
5 Cubes $(1-2-3-4-5) /$ Final & $20 / 25$ & $<.000000001$ \\
\hline
\end{tabular}


sequentially, items in the present study were simultaneously available. This opens the possibility that the subject was subitizing rather than counting. Subitizing is typically described as a direct perceptual apprehension of small numerical arrays as opposed to a formal enumerative process (for discussion, see von Glasersfeld, 1982). In the present context, however, this is not a critical distinction. Rather, we have attempted to demonstrate control by number, regardless of the means by which it was accomplished.

Although this report describes the first demonstration of sensitivity to number in a raccoon, it is by no means the first evidence of "intelligence" in this species. Reports over a 70-year period have stressed the discriminative capacities of raccoons (e.g., Cole, 1907; Davis, 1907). However, virtually all previous conditioning studies of the raccoon have involved fairly rudimentary discriminative tasks. In that regard, the present task may represent the most "cognitive" accomplishment to date with this species.

It is worth noting that our results, however positive, took considerable time to establish. Although counting or number sensitivity does typically require considerable time to develop, our work with the raccoon might have been facilitated by the use of tactual, rather than visual stimuli. During the adaptation phase of the experiment, it became obvious that Rocky often explored the cube and its contents without benefit of visual guidance. We noted that the subject often actively turned his head away while feeling for grapes with his paw (see Figure 4). This observation is consistent with anecdotal reports of foraging behavior by raccoons in which they are known to "hunt blind," for example, to reach into a hollow log or a pool of water in search of prey. That performance in such situations may be amply guided by tactual cues is supported by recent studies of the complex sensorineural organization of the raccoon's paw (Munger \& Pubols, 1972; Pubols \& Leroy, 1977).

Breland and Breland (1961) have suggested that the rac-

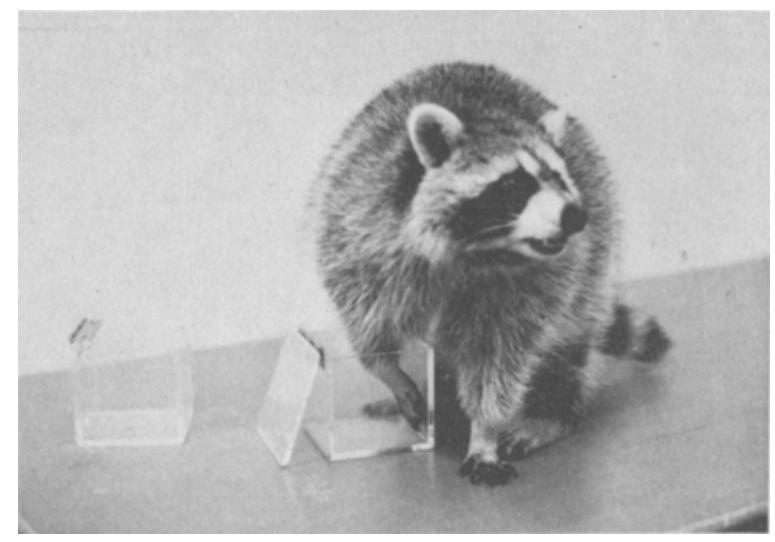

Figure 4. After opening the target cube containing three grapes, the raccoon often explored its contents in a manner that suggested the importance of tactual, rather than visual, cues. coon may not be an ideal subject for conditioning research. They described the problems they encountered in terms of "instinctive drift," the intrusion of naturally occurring behaviors into the learned patterns they were attempting to establish. Do our problems in the present experiment confirm this view of the raccoon? To be sure, Rocky's attention span was less than ideal, and he became extremely difficult to manage during the early spring, when more salient motivational states than "concern with number" were aroused. Nevertheless, it is possible that our decision not to food-deprive the subject contributed to the extensive time required for training. Certainly, the erratic and waning effects of various food reinforcers may be accounted for in this regard. In short, we chose to condition our subject using "treats" rather than employing primary reinforcement with a food-deprived subject, and in so doing we lost some degree of control over his behavior. If nothing else, this may have contributed to the relative potency of social reinforcement in the present study, both as a reward and a punishment in the form of time-outs.

We have previously argued that counting, or sensitivity to number, is a highly unnatural ability for infrahuman animals (Davis \& Memmott, 1982). There is nothing in the present findings to question that conclusion. In fact, the present results confirm and extend the work of others as well as our own previous results: Discriminative control based upon number may be taught to infrahuman subjects, but its development will be relatively slow and harder to maintain in comparison with more "prepared" associations (Seligman, 1970).

\section{REFERENCES}

Barash, D. P. (1974). Neighbor recognition in two "solitary" carnivores: The raccoon (Procyon lotor) and the red fox (Vulpes fulva). Science, 185, 794-796.

BIERENS DE HAAN, J. A. (1932). Über das Suchen nach serstecktem Futter bei einigen Procyoniden und einem Eichörnchen. Zeitschrifi für Vergleichende Physiologie, 17, 279-303.

Breland, K., \& Breland, M. (1961). The misbehavior of organisms. American Psychologist, 16, 681-684.

Cole, L. W. (1907). Concerning the intelligence of raccoons. Journal of Comparative Neurological Psychology, 17, 211-261.

DAVIS, H. (1907). The raccoon: A study in animal intelligence. American Journal of Psychology, 18, 441-489.

DAvis, H., \& MEмmotT, J. (1982). Counting behavior in animals: A critical evaluation. Psychological Bulletin, 92, 547-571.

Davis, H., \& Mеммотт, J. (1983). Autocontingencies: Rats count to three to predict safety from shock. Animal Learning \& Behavior, 11, 95-100.

FIELDS, P. E. (1936). Studies in concept formation. IV. A comparison of white rats and raccoons with respect to their visual discrimination of certain geometric figures. Journal of Comparative Psychology, 21, 341-355.

Hicks, L. H. (1956). An analysis of number concept formation in the rhesus monkey. Journal of Comparative and Physiological Psychology, 49, 212-218.

JoHNSon, J. I., \& MChels, K. M. (1958). Discrimination of small intervals and objects by raccoons. Animal Behaviour, 6, 164-170.

Munger, B. L., \& Pubols, L. M. (1972). The sensorineural organization of the digital skin of the raccoon. Brain, Behavior \& Evolution, 5, 367-393. 
MunN, N. L. (1930). Pattern and brightness discrimination in raccoons. Journal of Genetic Psychology, 37, 3-34.

MURPHY, M. G., \& O'LEARY, J. L. (1973). Hanging and climbing functions in raccoon and sloth after total cerebellectomy. Archives of Neurology, 28, 111-117.

Pubols, L. M., \& Leroy, R. F. (1977). Orientation detectors in the primary somatosensory neocortex of the raccoon. Brain Research, 129, 61-74.

Rabinowitz, A. R. (1981). The ecology of the raccoon (Procyon lotor) in Cades Cove, Great Smoky Mountain National Park. Unpublished doctoral dissertation, University of Tennessee.

Seligman, M. E. P. (1970). On the generality of the laws of learning. Psychological Review, 77, 406-418.
SHELl, W. F., \& RJOPELLE, A. J. (1957). Multiple discrimination learning in raccoons. Journal of Comparative and Physiological Psychology, 50, 585-587.

VON Glasersfe LD, E. (1982). Subitizing: The role of figural patterns in the development of numerical concepts. Archives de Psychologie, 50, 191-218.

WARREN, J. M., \& WARREN, H. B. (1962). Reversal learning by horse and raccoon. Journal of Genetic Psychology, 100, 215-220.

WATSON, J. B. (1914). Behavior: An introduction to comparative psychology. New York: Holt, Rinehart \& Winston.

(Manuscript received February 9, 1984; revision accepted for publication June 6,1984 .) 